\title{
Factors Related to Students' Drop Out of a Distance Language Learning Programme
}

\author{
Rahmat Budiman ${ }^{1, *}$ \\ ${ }^{1}$ Universitas Terbuka, Pamulang, Indonesia \\ *Correspondence: Universitas Terbuka, Pamulang, Indonesia. E-mail: budiman@ecampus.ut.ac.id
}

Received: May 15, $2018 \quad$ Accepted: June 26, 2018 Online Published: August 3, 2018

doi:10.5430/jct.v7n2p12

URL: https://doi.org/10.5430/jct.v7n2p12

\begin{abstract}
This paper presents a study that examined the reasons for dropping out of a distance language learning programme offered by an open university in Indonesia. A purposive sample of students who registered for online English writing courses at the university was used. To gain a better understanding of the issues, the study also sought information from online tutors. A longitudinal research design employing qualitative research method was used over four stages of data collection. Open-ended question surveys were adopted to gain an understanding of underlying reasons for persisting or discontinuing their studies. Semi-structured interviews were conducted at each stage to obtain deeper information from the students and the online tutors. The data was analysed with NVivo version 10 . The findings of the open-ended question surveys and the interviews indicated that the major reasons that led the students to drop out were lack of basic skills in English, unmet expectations, feelings of isolation, and the inability to balance work, family, and study responsibilities. The study offers a theoretical framework to describe the factors related to student dropout from a distance language learning programme. This study also offers models of interaction, teaching and learning in distance language learning to minimise the dropout rate.
\end{abstract}

Keywords: distance learning, dropout, English writing, Indonesia

\section{Introduction}

This paper focuses on reporting the results of the exploration and investigation of the factors related to drop out in the distance learning context. The idea to focus on student dropout originated from the situation that there has been a decline in the number of students who proceed to the higher levels of a set of English writing courses offered at a distance learning university in Indonesia.(Note 1) Thus, measures need to be taken to support the students and improve student retention.

The term drop out is amenable to a number of interpretations (Cambruzzi, Rigo, \& Barbosa, 2015). The researcher, however, would agree with Powell (2009) that the term "drop out" used in open and distance education is not the same as that used in a conventional university, as open and distance students can resume their studies at any time. The term "drop out" is selected here as the students admitted that they would not continue their studies. In practice, they might continue their studies sometime in the future.

Unlike students of conventional universities, physically, distance learning students are separated from the instructors and the other students in terms of time and space (Rashid, Jahan, Islam, \& Ratna, 2015). Although modern information communication technology has been used widely in distance learning, Budiman (2015a) found that the separation of the students from the instructors and the other students may lead to drop out. Thus, student retention, persistence, and graduation have long been a concern to policy makers and institutions (Swail, 2014).

In terms of challenges, Brown, Hughes, Keppell, Hard, and Smith (2015) carried out a study on the experience of first time distance students at Charles Sturt University, Australia and Massey University, New Zealand. The authors identified challenges faced by first time distance students, including employment and family responsibilities, home environment, prior educational experience, health and wellbeing, digital literacy, and personal activities. Conventional students may not meet the challenges. In addition, Musingafi, Mapuranga, Chiwanza, and Zebron (2015) who investigated the challenges facing Open and Distance Learning students at the Zimbabwe Open University (ZOU) listed a number of factors that were considered as major challenges. The authors broke down the challenges into three sub-categories: individual, instructional, and institutional challenges. Individual challenges 
came from the students, including lack of study time, ICT literacy, financial constraints, and transportation issues. Instructional challenges were majority related to delay of feedback. Meanwhile, institutional challenges were delayed order or unavailable study materials, and inadequate academic support. In general, therefore, it suggests that distance students face many more challenges, compared to conventional students.

\section{Student Dropout in Distance Learning}

Early exit seems to be a common phenomenon in distance learning. A systematic search to identify previous research of student dropout of distance and e-learning institutions found that student dropout is a complex issue. Boateng and Boadu (2013) listed nineteen factors that related dropout. Factors that received attention from the students were lack of communication between students and instructors, inability to understand the course content, inability to collaborate with other students, and low quality of teaching and instructors. These findings suggest that quality interaction between students and students as well as between students and instructors seem to play important role in the distance learning process. Rashid et al. (2015) categorised factors related to student dropout into two groups; intrinsic and extrinsic factors. Extrinsic factors that were associated with dropout were employment responsibilities, financial constraints, and low academic capability. Meanwhile, extrinsic factors included in sufficient academic support from the institution, and less interaction. Similar findings were identified in a study of Budiman (2015b) who investigated factors that related to student achievement and drop out. It could be argued that reasons for dropping out of distance education program were numerous.

In a study investigating reasons for attrition in Massive Open Online Courses (MOOCs) context, Yang, Sinha, Adamson, and Rosé (2013) reported that there was a strong correlation between course completion and social connectedness. The finding of the study might suggest that social connection fosters academic success. Meanwhile, Yukselturk, Ozekes, and Türel (2014) using data mining methods found that limited online technologies self-efficacy, online learning readiness, and previous online experience were among factors that may lead students to drop out. A more recent study by Oliveira, Oesterreich, and Almeida (2017) that involved graduate distance students of Universidade Aberta do Brasil found that family commitments, health condition, and age were significant predictor of persistence.

\section{Strategies to Improve Dropout Rate}

Baruah (2011) who investigated student retentions at a distance learning university in India suggested that E-learning technology was useful in reducing attrition rate. Furthermore, Baruah suggested that the instructional technology to be used should be in line with the characteristics of the programme. A more recent study conducted by Yang et al. (2013) in the context of Massive Open Online Courses (MOOCs) indicated that the attrition rate was influenced by strong commitment which was built through social engagement.

In an e-learning context, Tobin (2014) maintained that the use of Universal Design for Learning (UDL) might help students to break down barriers that hindered students from establishing networks of connection with the instructors and the institution. Considering all this evidence, it could be argued that interaction between students and students and students and instructors seems to be a key point in distance and e-learning environment.

\section{Research Question and Designs}

The research questions originated from the researcher's concern about the fact that a large number of students did not proceed to the higher levels of an English writing course at a distance learning university in Indonesia. The research question was what caused students to drop out of the programme.

The participants were the students who registered for the Writing 1 course in Semester 2 of 2012. Sampling a cohort of students until they registered for the Writing 4 course enabled identification of students who did not proceed to the next level of the English course. With regard to Cohen, Manion, and Morrison (2011), this study employed a longitudinal cohort study that used qualitative methods.

Four hundred and five students took the Writing 1 examination and they were all invited to participate in the survey as an entire cohort of students. This cohort became the focus of data collection over four stages. Consent letters were sent together with the surveys and the interview invitation letters. It was clearly stated that participation in the research was elective. In addition, it covered a guarantee to protect anonymity and confidentiality. The interviews were conducted with those who signed and returned the interview consent letters. Prior to the interviews, the interviewers would read again the interview consent letter signed by the interviewees in case they would like to 
withdraw. The number of participants for each data collection can be seen in Table 1 below.

Table 1. Participant Size

\begin{tabular}{lcc}
\hline Stage & \multicolumn{2}{c}{ Number of Participants } \\
\cline { 2 - 3 } & Survey & Interview \\
\hline One & 164 & 10 \\
Two & 52 & 8 \\
Three & 25 & 6 \\
Four & 16 & 8 \\
\hline
\end{tabular}

\section{Analysis and Results}

The data from the surveys and the interview transcripts were analysed using Newby's (2010) four stages of the process, including preparing the data, identifying basic units of data, organising data, and interpreting of data. In addition, to enhance trustworthiness, a flow of work introduced by Shenton (2004) was adopted, including asking peers for feedback on the procedures taken, asking the interviewees to read the interview transcripts to check whether the information given was correct, and asking counterparts to identify important issues and themes in two selected interview transcripts to triangulate the outcomes for accuracy.

It is generally thought that non-completion rates among distance learning students are higher than students attending conventional universities (Inkelaar \& Simpson, 2015). In the first, second, and fourth stages of the study, some students attempted to exit the Programme of Study. However, their actual departure happened in the first and second stages. This information was indicated by the students in the surveys to find out the reasons for not progressing. The student dropout rate declined in the following semesters. This might indicate that the students were more persistent. Some students admitted that they were able to internalise the principles of distance learning, including regulating self-managed learning, setting a target to achieve and looking for opportunities to study.

A lack of basic skills of English and the inability to maintain a balance between study, work, and life, particularly for those in employment, were identified as the two major findings from the study. A closer look at the findings of the current study reveals that dropouts fall into two types: students who directly leave the Programme of Study once they fail in the first examination and those who remain in the Programme of Study, but eventually quit because they are not able to improve their English skills. These findings are consistent with other research findings, which found that the achievement and satisfaction are predictors of student persistence (Joo, Lim, \& Kim, 2013). In other words, achievement is a factor that influences whether a student continues their study or drops out.

A lack of basic skills of English coupled with family and employment responsibilities and a lack of support from the university (lecturers and tutors), particularly in the form of feedback provisions and peer interactions often lead students to drop out of the programme. This finding-supports the findings of the search conducted by Musingafi et al. (2015), Rashid et al. (2015), and Budiman (2015b).

\subsection{Lack of Basic Skills of English}

This study found that early dropout was strongly linked to a lack of basic skills in English. Lacking basic skills in English makes it difficult for students to follow the courses, which eventually affects their achievement. The findings of the current study showed that at Stage 1, despite being able to resit examinations, a student decided to exit from the Programme of Study because of failure to pass the examination. The finding seems to be consistent with Boateng and Boadu (2013) and Rashid et al. (2015) who low academic capability is a reason to consider signing off on the program.

Another student left because of the accumulation of not having strong basic skills and poor expectations. Some participants who were new to distance learning system were expecting to have regular face-to-face meetings with instructors. Furthermore, the data from the interviews with tutors show that there is a missing link in communication between the program and the students. A tutor mentioned that the program requires an intermediate level of English proficiency. The finding is also in agreement with Yukselturk et.al's (2014) findings which show that lack of prerequisite knowledge affects the students' decision to drop out. These findings suggest that there is a need for specific guidance for students to understand the programme prior to enrolling on the programme itself. 


\subsection{Inability to Balance Family, Employment and Study Responsibilities}

The findings of this study show that students in employment have difficulties balancing work and study responsibilities, which affects their study time and eventually their achievement in the examinations. The data show that study responsibilities often interfere with family and employment responsibilities, which in turn lead to the decision to drop out of the programme. The current study shows that family and work responsibilities often lead students to give up their study, especially those students whose employment/employers are not supportive. These findings were consistent with those of Oliveira et al. (2017) and Rashid et al. (2015) who found that family and employment responsibilities were associated with dropout.

The current study found that a small number of students with high motivation, strong goal commitment and supportive employment were committed to studying although their working hours were long. This finding corroborates the findings of Colorado and Eberle (2012) who found that working hours per week did not correlate with academic performance in an online program.

\subsection{Other Possible Reasons for Dropping Out}

Despite being separated from peers and institutions is the nature of distance learning, new distance learning students often find it difficult to develop self-managed learning, which, in turn, makes them feel alone and isolated. In the current study, feeling alone and isolated, particularly happened to students who did not participate in the online tutorials. However, the current study also suggested that participating in the online tutorial did not immediately free the students from feeling isolated. A possible reason for this situation was that the number of tutees in one online tutorial class was so large that it prevented the tutors from developing direct interaction with the tutees and among the tutees. The current study also found that a potential cause of student resignation is the feeling of isolation. In Stage 3, it was found that feeling isolated, as well as long working hours and personal and family responsibilities lead students to take a study break. The researcher strongly believes that if these problems remain unsolved, this might in turn lead to dropping out. In terms of feelings of isolation, this finding is in accord with the studies conducted by Boateng and Boadu (2013) and Yang et al. (2013) indicating that connectedness is a central issue in distance and e-learning context.

The other possible reason for dropping out of the programme is financial challenges. Interviews with students in the last stage revealed that economic and financial challenges might force them to quit the programme of studies. These findings are consistent with Musingafi et al's., (2015) findings, which showed that financial difficulties experienced by students may result in having a serious problem in completing their studies. In this current study, the students, however, suggested that instead of resigning from the programme of studies, they would take a study break so that that can resume their studies at any time.

The current study established a theoretical framework for student dropout of distance language learning. Although there are some models of dropping out from distance education (Kember, 1989), based on the findings on student achievement and dropout this study proposes a theoretical framework of dropping out of distance learning (see Figure 1 below).

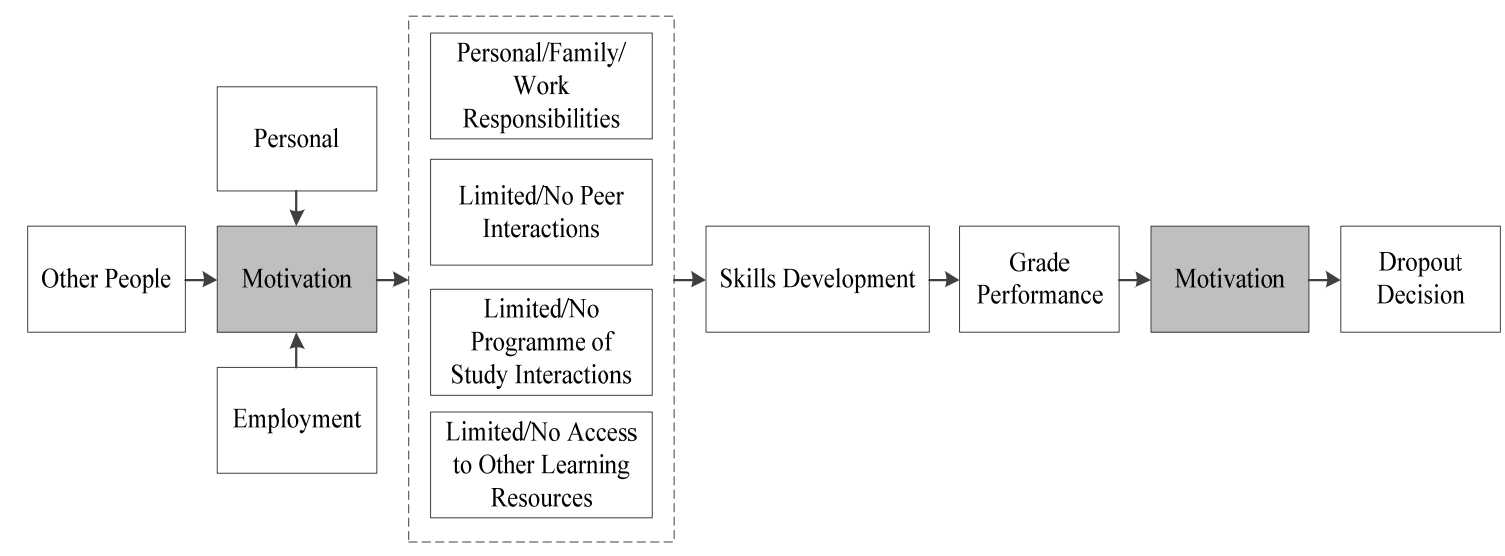

Figure 1. Theoretical Framework for Dropping Out from a Distance Language Learning Programme 
The main findings that might explain the decision to drop out of the programme of studies were found in the first and second stage. It could be argued that the first two semesters of the programme are critical as learning under a distance mode is new for most students. The current study showed that some students enrolling on the programme of studies have very limited knowledge and understanding of distance learning, including self-managed learning.

Motivation plays an important role in determining student progress (Rashid et al., 2015). It is clear that motivation to study varied among the students of this study. However, the findings of the current study suggest that motivation depends on both intrinsic (personal) and extrinsic (other people and employer/employment) motivation. Intrinsic motivation might be personal commitment or positive spirit, while extrinsic motivation might be the influence of other people, including family, employer/employment, peers and partners.

The current study showed that individual motivation and commitment are often disrupted during the learning process. The disruptions to motivation could be from family and employment responsibilities for those who are married or in employment, and from minimum (or no) interaction with peers, lecturers, and online tutors. Inability to cope with disruptions has an impact on skills development, which eventually affects grade performance. Motivation and the ability to maintain motivation have been identified as contributing factors to successful distance learning in an English writing course in this study. This is supported by Xiao (2012) who found that motivation influences success in distance English language learning.

The current study showed that attaining low grades in examinations and making little progress in writing skills contribute towards the decision to drop out of the Programme of Study. This finding is also reported by Rashid et al. (2015). To minimise student drop out in a distance learning context, the researcher proposed an alternative model to assist institutions and policy maker in reducing dropout rates. The following figure illustrates the process.

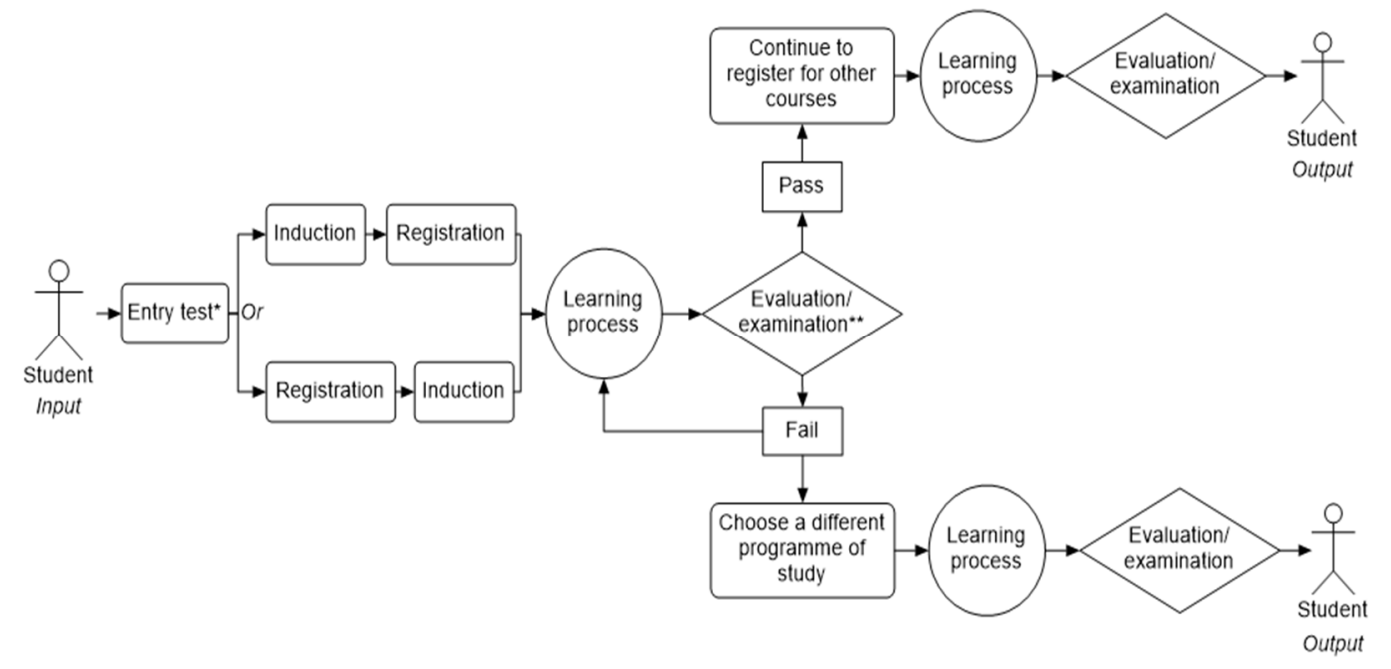

Figure 2. A Model of the Student Recruitment Process and Procedure to Improve Learning Process and Minimise Dropout Rate

Thomas (2013) argued that good information at pre-entry helps distance student candidates avoid abrupt transitions, which in turn improves student satisfaction and retention. One of the procedures to identify distance student candidates is through an entry test. The entry test for admission can be conducted through an online self-test where candidates are able to examine their skills and knowledge of English language and also examine Information and Communication Technology literacy. In the researcher's experience of working as a distance learning lecturer, the researcher sometimes meets students who register for a programme of study without examining the Programme of Study or who choose a programme of study simply because of the fact that their friends have previously registered on the Programme of Study.

Although the university where the study took place applies minimum requirements at the admission stage, defining requirements other than educational qualifications to enrol in certain programmes of studies could be applied to minimise the rate of dropout. Instead of pass or fail results, the results of the entry test might be in the form of advice and recommendations about whether the candidates have the minimum requirements to join the Programme of Study. Those who do not meet the requirements could be recommended to choose other programmes of studies or to ask 
lecturers for academic advice. It could be argued that this procedure would facilitate the candidates' awareness of their expectations and the Programme of Study's expectations as well as the development of distance learning responsibilities. Thus, communication could be developed before the students begin their studies. Thus, instructors may understand the students' needs and capacities.

Another line of thought on improving the language teaching-learning process in distance learning is to have an induction experience. At the induction, candidates could establish firmer expectations about the distance learning system, including how to register for courses, academic counselling, independent learning, online tutorials, examinations, prerequisite skills and technical requirements for the programme. Enhancing student transition, particularly in the first year has become an institutional priority (Thomas, 2013). This practice reflects the principle of andragogy (Knowles, Holton, \& Swanson, 2005). A good induction might ensure the students are well prepared and well informed which, in turn, would help them adjust to the new learning arrangements. Induction could be conducted through computer-mediated presentations followed by some multiple-choice questions to ensure that students understand the presentations. Universitas Terbuka, for example, conducted a half-day orientation programme by introducing distance learning to new students held in each Regional Office (Universitas Terbuka, 2015). Of course, it is possible that not all new students would be keen to attend the orientation, especially those who have family and employment responsibilities. Thus, the researcher believes that asynchronous online induction offers greater benefits than on-site orientation. A future study investigating on-site and online induction/orientation would be very interesting.

Once the students are ready, they could register for some basic courses offered in the early semesters. After one semester, the lecturers identify the students' progress. Students who fail or show little improvement after one semester could be recommended to choose another programme of studies or receive special treatment for improvement. This shows that academic counselling is very important, even in distance learning. A one-to-one counselling either with academic advisors at the Regional Offices or at the study programmes can be conducted through various technological devices. Therefore, the researcher would propose a model of the student recruitment process and procedure in order to improve the learning process and minimise the dropout rate.

The model demonstrates admission and student recruitment processes in distance learning. By applying this model, students who face learning difficulties that might lead them to drop out could be identified at the early stages and they might benefit from having consultation with the lecturers both synchronously and asynchronously.

\section{Summary and Conclusions}

Based on the data analyses, it has been found that there are two major issues which lead students to drop out of the programme. Lack of basic skills of English and unmet expectations are two major causes of early exits. For working students, the inability to balance work, family and study responsibilities is the other issue that appears to lead them to drop out. It was also found that financial difficulty is another possible issue that might lead students to drop out.

Taken together, the findings of all studies suggest that distance learning students should be well prepared prior to enrolling on the programme. Students should understand that a distance learning university is different from a conventional university. This may also imply that distance learning universities should ensure that information about their distance learning system is accessible to anyone. ICT literacy should be a part of the curriculum. Equally important, connectedness and support from family, employment, peers and institutions are essential elements in the whole process of learning in a distance learning context.

\section{Acknowledgement}

This manuscript was presented at the 3rd e-Learning and Distance Education Conference, 14-15 March 2016 Lahore, Pakistan.

\section{References}

Baruah, T. D. (2011). Improving Student Retention through Technology in India. Asian Journal of Distance Education, 9(2), 15-25. $\quad$ Retrieved from https://s3.amazonaws.com/academia.edu.documents/8064657/2011v9.2.baruah.pdf?AWSAccessKeyId=AKIAI WOWYYGZ2Y53UL3A\&Expires=1526350414\&Signature=NQFDiEiTXhDbKHH4\%2FlziWtBxbkM\%3D\&r esponse-content-disposition=inline\%3B\%20filename\%3DImproving_Student_Retention_through_Tech.pdf 
Boateng, C. A., \& Boadu, K. (2013). Reducing Distance Learners' Attrition Rate at the University of Cape Coast: Tutors'/Students' Perception. International Journal of Learning and Development, 3(3), 214. http://dx.doi.org/10.5296/ijld.v3i3.4068

Brown, M., Hughes, H., Keppell, M., Hard, N., \& Smith, L. (2015). Stories from Students in Their First Semester of Distance Learning. The International Review of Research in Open and Distributed Learning, 16(4). https://doi.org/10.19173/irrodl.v16i4.1647

Budiman, R. (2015a). Distance Language Learning: Students'views of Challenges And Solutions. International Journal on New Trends in Education, 6(3), 137-147.

Budiman, R. (2015b). A Longitudinal Study of Student Achievement and Dropout in a Distance Learning English Writing Course. University of Dundee.

Cambruzzi, W. L., Rigo, S. J., \& Barbosa, J. L. (2015). Dropout Prediction and Reduction in Distance Education Courses with the Learning Analytics Multitrail Approach. J. UCS, 21(1), 23-47.

Cohen, L., Manion, L., \& Morrison, K. (2011). Research Methods in Education (7th ed.). Oxon: Routledge.

Colorado, J. T., \& Eberle, J. (2012). Student demographics and success in online learning environments. Emporia State Research Studies, 46(1), 4-10.

Inkelaar, T., \& Simpson, O. (2015). Challenging the 'distance education deficit' through 'motivational emails'. Open Learning: The Journal of Open, Distance and e-Learning, 30(2), 152-163. http://dx.doi.org/10.1080/02680513.2015.1055718

Joo, Y. J., Lim, K. Y., \& Kim, J. (2013). Locus of Control, Self-Efficacy, and Task Value as Predictors of Learning Outcome in an Online University Context. Computers \& Education, 62(0), 149-158. http://dx.doi.org/10.1016/j.compedu.2012.10.027

Kember, D. (1989). A Longitudinal-Process Model of Drop-Out from Distance Education. The Journal of Higher Education, 60(3), 278-301. https://doi.org/10.2307/1982251

Knowles, M. S., Holton, E. F., \& Swanson, R. A. (2005). The Adult Learner: The Definitive Classic in Adult Education and Human Resource Development (6th ed.). Amsterdam: Elsevier Butterworth Heinemann.

Musingafi, M. C., Mapuranga, B., Chiwanza, K., \& Zebron, S. (2015). Challenges for Open and Distance Learning (ODL) Students: Experiences from Students of the Zimbabwe Open University. Journal of Education and Practice, 6(18), 59-66.

Newby, P. (2010). Research Methods for Education. Essex: Pearson.

Oliveira, P. R. d., Oesterreich, S. A., \& Almeida, V. L. d. (2017). School dropout in graduate distance education: evidence from a study in the interior of Brazil. Educação $e$ Pesquisa, 44, 1-20. https://doi.org/4634201708165786

Powell, R. (2009). Openness and dropout: A study of four open distance education universities. Paper presented at the M-2009: 23rd International Council on Distance Education World Conference on Open Learning and Distance Education.

Rashid, M. M., Jahan, M., Islam, M. A., \& Ratna, M. M. (2015). Student Enrollment and Dropout: An Evaluation Study of Diploma in Computer Science and Application Program at Bangladesh Open University. The International Review of Research in Open and Distributed Learning, 16(4), 18-32. https://doi.org/10.19173/irrodl.v16i4.2157

Shenton, A. K. (2004). Strategies for Ensuring Trustworthiness in Qualitative Research Projects. Education for Information, 22(2), 63-75. https://doi.org/10.3233/EFI-2004-22201

Swail, W. S. (2014). A Different Viewpoint on Student Retention Higher Learning Research Communication, 4(2), 18-25. Retrieved from http://educationalpolicy.org/publications/pubpdf/140714_Journal_Article.pdf

Thomas, L. (2013). What works? Facilitating an effective transition into higher education. Widening Participation and Lifelong Learning, 14(1), 4-24. https://doi.org/10.5456/WPLL.14.S.4

Tobin, T. J. (2014). Increase Online student Retention with Universal Design for Learning. Quarterly Review of Distance Education, 15(3). 
Universitas Terbuka. (2015). Katalog Sistem Penyelenggaraan Program Non Pendas Universitas Terbuka 2015. Jakarta: Universitas Terbuka.

Xiao, J. (2012). Successful and Unsuccessful Distance Language Learners: An 'Affective' Perspective. Open Learning: The Journal of Open, Distance and e-Learning, 27(2), 121-136. http://dx.doi.org/10.1080/02680513.2012.678611

Yang, D., Sinha, T., Adamson, D., \& Rosé, C. P. (2013). Turn On, Tune In, Drop Out: Anticipating student dropouts in Massive Open Online Courses. Paper presented at the Proceedings of the 2013 NIPS Data-driven education workshop, Nevada.

Yukselturk, E., Ozekes, S., \& Türel, Y. K. (2014). Predicting Dropout Student: An Application of Data Mining Methods in an Online Education Program. European Journal of Open, Distance and E-learning, 17(1), $118-133$. https://doi.org/10.2478/eurodl-2014-0008

\section{Note}

Note 1. To maintain compliance with ethics principles, the name of the university remains anonymous 